\title{
CORRELATION OF FRACTURE SURFACE TOPOGRAPHY AND TRANSITION BEHAVIOR OF NODULAR CAST IRON
}

Dynamic testing methods, especially the Charpy V-notch testing at different temperatures, are commonly used to determine the impact response of metallic materials. However, in nodular cast iron this transition trend is characterized by scatter, which makes it difficult to precisely identify the influence of microstructural features on material response. In this paper the vertical surface roughness parameter $R_{V}$ obtained from fracture profiles is considered on the hypothesis that the surface topography is a sensitive indicator of the energy absorbed by plastic deformation and of the microstructure. Nodular cast irons having a range of microstructures were impact tested and the surface roughness determined. Transition trends of impact toughness and of $R_{V}$ are discussed.

\section{Introduction}

Nodular cast iron is preferred to grey cast iron in many engineering applications where high strength and high impact toughness are required, [1]. Previous studies, [2, 3], showed that ductile iron has a pronounced ductile-to-brittle transition i.e. the change in fracture response from ductile to brittle with an increase in test temperature. Most alloying elements or impurities affect toughness indirectly through their effect on graphite morphology and matrix microstructure. An increase in silicon and carbon content increases the number of crystallizing nuclei and, consequently, the number of graphite nodules with an increase in the transition temperature. The effect of graphite morphology is especially significant for upper-shelf toughness (ductile response) and very limited below the transition temperature, [4]. Addition of copper or tin favours the development of a pearlite matrix with an expected decrease in impact toughness.

Dynamic testing methods, especially the Charpy V-notch testing at different temperatures, are commonly used to identify the impact response of metallic materials. Test data associated to the transition behavior are normally presented in the form of $K C V \mathrm{vs}$. $T$ plot and are often characterized by a $S$-shaped trend. However, in nodular cast iron this transition trend is accompanied by scatter and the scatter increases with material heterogeneity as the notch selectively initiates failure at different microstructural locations. The data scatter makes it then difficult to precisely identify the influence of microstructural features, such as shape, size and number of graphite nodules or matrix structure (i.e. pearlite/ferrite ratio, for example) on material response.

The previous considerations suggest the importance of identifying and evaluating parameters, other than the absorbed impact energy, that could provide insight of the microstructural contribution to the material response. In this paper the vertical surface roughness parameter $R_{V}$ of the fracture profile will be considered on the hypothesis that the surface topography is a sensitive indicator of both the energy absorbed by plastic deformation during an impact test and the material microstructure. Therefore notch and unnotched impact tests performed on different melts of nodular cast iron having a great range of microstructure are examined. Their transition behavior is also characterized by Charpy $V$-notch tests at different temperatures. The vertical surface roughness is then obtained from profiles of the failed specimens and assessed in its ability to discriminate the role of microstructural details on material response.

\section{Experimental details}

\subsection{Materials and microstructure}

Twelve melts of nodular cast irons were produced with the aim of obtaining a wide variety of microstructures, especially in terms of ferrite-to-pearlite ratio. Details of charge composition, type of modifier and inoculation of the ductile irons as well as the chemical composition of the melts are given elsewhere, [2]. The microstructures of the nodular cast iron were characterized according to the following parameters: percentage of perfectly round nodules, nodule count (number of nodules $/ \mathrm{mm}^{2}$ ) and percentage of effective ferrite phase in the matrix, see Tab. 1 (D identifies melts with $\mathrm{FeSi}$ addition and $\mathrm{E}$ with $\mathrm{SiC}$ addition). Basic mechanical properties, such as hardness, ultimate strength and elongation to rupture, are also given in Tab. 1.

\subsection{Impact toughness testing}

The Charpy V-notch dynamic test method is commonly used to identify the impact response of metallic materials. To deter-

\footnotetext{
* Gianni Nicoletto ${ }^{1}$, Radomila Konečná ${ }^{2}$

${ }^{1}$ Dept. of Industrial Engineering, University of Parma, 43100 Parma, Italy, e-mail: nick@me.unipr.it,

${ }^{2}$ Dept. of Materials Engineering, Žilina University, 01026 Žilina, Slovakia, e-mail: radomila_konecna@kmi.utc.sk
} 
Microstructure and mechanical properties of melts of nodular cast iron

Table 1

\begin{tabular}{|c|c|c|c|c|c|c|c|c|c|}
\hline Melt & $\begin{array}{l}\text { Graphite form } \\
\text { STN } 420461\end{array}$ & Matrix & $\begin{array}{c}\text { Nodule } \\
\text { count } \\
{\left[\mathrm{mm}^{-2}\right]}\end{array}$ & $\begin{array}{c}\text { Effective } \\
\text { ferrite } \\
{[\%]}\end{array}$ & $\mathrm{HB}$ & $\begin{array}{c}\mathrm{R}_{\mathrm{m}} \\
{[\mathrm{MPa}]}\end{array}$ & $\begin{array}{l}\mathrm{A}_{5} \\
{[\%]}\end{array}$ & $\begin{array}{c}\mathrm{KC} 0 \\
{\left[\mathrm{~J} / \mathrm{cm}^{2}\right]}\end{array}$ & $\begin{array}{c}\mathrm{KCV} \\
{\left[\mathrm{J} / \mathrm{cm}^{2}\right]}\end{array}$ \\
\hline D 1756 & $80 \% \mathrm{VI} 5+20 \% \mathrm{~V} 6$ & $\mathrm{Fe} 30$ & 83 & 29.6 & 249 & 744 & 7 & 11 & 4.5 \\
\hline D 1579 & $70 \% \mathrm{VI} 5+30 \% \mathrm{~V} 6$ & Fe 55 & 100 & 66.8 & 203 & 709 & 3 & 16 & 3.6 \\
\hline D 1248 & $90 \% \mathrm{VI} 6+10 \% \mathrm{~V} 7$ & Fe 80 & 113 & 71.4 & 205 & 550 & 12 & 16 & 5.5 \\
\hline D 1674 & $70 \% \mathrm{VI} 6+30 \% \mathrm{V7}$ & $\mathrm{Fe} 80$ & 119 & 71.8 & 181 & 564 & 7 & 49 & 6.1 \\
\hline E 164 & $90 \% \mathrm{VI} 5+10 \% \mathrm{~V} 6$ & Fe 30 & 92 & 21.2 & 201 & 774 & 8 & 14 & 3.7 \\
\hline E 158 & $70 \% \mathrm{VI} 5+30 \% \mathrm{~V} 7$ & $\mathrm{Fe} 30$ & 96 & 24.0 & 221 & 774 & 6 & 11 & 3.4 \\
\hline E 151 & $70 \% \mathrm{VI} 6+30 \% \mathrm{~V} 6$ & Fe 55 & 117 & 49.8 & 216 & 564 & 12 & 6 & 5.6 \\
\hline E 148 & $80 \% \mathrm{VI} 6+20 \% \mathrm{~V} 7$ & $\mathrm{Fe} 80$ & 121 & 73.4 & 170 & 576 & 15 & 51 & 7.1 \\
\hline E 144 & $80 \% \mathrm{VI} 7+20 \% \mathrm{~V} 7$ & $\mathrm{Fe} 80$ & 131 & 75.6 & 174 & 537 & 16 & 69 & 6.3 \\
\hline E 152 & $90 \% \mathrm{VI} 7+10 \% \mathrm{~V} 7$ & $\mathrm{Fe} 94$ & 160 & 77.6 & 194 & 554 & 13 & 38 & 6.3 \\
\hline E 153 & $80 \% \mathrm{VI} 7+20 \% \mathrm{~V} 7$ & Fe 94 & 174 & 80.2 & 178 & 530 & 13 & 90 & 5.2 \\
\hline E 171 & $90 \% \mathrm{VI} 7+10 \% \mathrm{~V} 8$ & $\mathrm{Fe} 94$ & 196 & 81.2 & 174 & 537 & 15 & 75 & 8.2 \\
\hline
\end{tabular}

mine the transition behavior, Charpy V-notched specimens (prismatic bars $10 \times 10 \times 50 \mathrm{~mm}$ ) are tested at different temperatures. In this study tests were performed at temperatures ranging from $-10{ }^{\circ} \mathrm{C}$ to $180^{\circ} \mathrm{C}$. The Charpy-notch impact toughness is defined as $\mathrm{KCV}\left(\right.$ in $\mathrm{J} / \mathrm{cm}^{2}$ ). Following a norm suggesting the use of the same prismatic bar but without notch for the impact characterization of cast iron, extensive unnotched bar tests were also performed at room temperature. In this case the unnotch impact toughness is defined as $\mathrm{KCO}\left(\mathrm{in} \mathrm{J} / \mathrm{cm}^{2}\right)$. The experimental impact toughness data for the twelve melts of this study are presented in Tab. 1. Following impact testing, a thorough microfractographic investigation of the fracture surfaces was performed in the SEM to highlight the change in failure mechanisms due to the ductilebrittle transition behavior and was reported in [3].

\subsection{Fracture surface roughness measurement}

Nodular cast iron is relatively brittle, so limited energy is dissipated during crack propagation by impact. Following the hypothesis that fracture surface topography of impacted specimens is a sensitive indicator of both the energy absorbed by plastic deformation and of the material microstructure, the vertical surface roughness parameter $R_{V}$ of the fracture profile was considered [5]. Fig. 1 shows typical micrographs of fracture profiles where dimples and extensive plastic deformation of ferrite when tested at high temperature and cleavage areas in ferrite when tested at low temperature are observed. Therefore, intuitively a high roughness is an indication of a significant contribution of ductile mechanisms.

The vertical surface roughness parameter $R_{V}$ of the fracture surface was determined by analysis of the fracture profile, see Fig. 2. The $R_{V}$ parameter (i.e. Behrens' roughness parameter) was quantitatively evaluated using the following relationship, [5],

$$
R_{V}=\frac{y}{L^{\prime}} \Sigma P_{i}
$$

where $P_{i}$ is the number of intersections of the magnified (250x) fracture profile with a superposed grid of horizontal lines, $y$ is the spacing of these grid lines (i.e. $y=2 \mathrm{~mm}$ ) and $L^{\prime}$ is the measurement base length $\left(\mathrm{L}^{\prime}=150 \mathrm{~mm}\right)$.

\section{Results and discussion}

\subsection{Ductile-brittle transition behavior}

In this section the role of ferrite in the matrix on the transition behavior of nodular cast iron is examined as obtained by Charpy $V$-notch impact tests at temperatures ranging from $-10{ }^{\circ} \mathrm{C}$ to $180^{\circ} \mathrm{C}$. The response of essentially ferritic (Fe 94 ) nodular cast irons is shown in Fig. 3. The classical S-shaped trend signalling the transition behavior from ductile to brittle is observed with a change in KCV from $20 \mathrm{~J} / \mathrm{cm}^{2}$ down to $5 \mathrm{~J} / \mathrm{cm}^{2}$. The classical sigmoidal equation is best fitted to all the experimental results and a value of $70{ }^{\circ} \mathrm{C}$ is found for the transition temperature $\mathrm{T} 0$, defined as the temperature associated to the average of the two asymptotic $K C V$ values. The scatter is relatively limited in this case.

Fig. 4 shows the transition curves for nodular cast iron having similar ferrite content ( $\mathrm{Fe} 80)$ in the matrix but two different additions (i.e. $\mathrm{SiC}$ vs. $\mathrm{FeSi}$ ) in the melt charge. In this case it is possible to discriminate two distinct transition curves although the scatter is larger than before. Furthermore, the SiC-added nodular cast iron presents a well-defined sigmoidal trend with two asymptotes and a transition temperature $\mathrm{T} 0$ of $85^{\circ} \mathrm{C}$. The FeSi-added nodular cast iron, on the other hand, shows a large scatter and an incomplete transition trend although a $\mathrm{T} 0$ of $108{ }^{\circ} \mathrm{C}$ can be esti- 


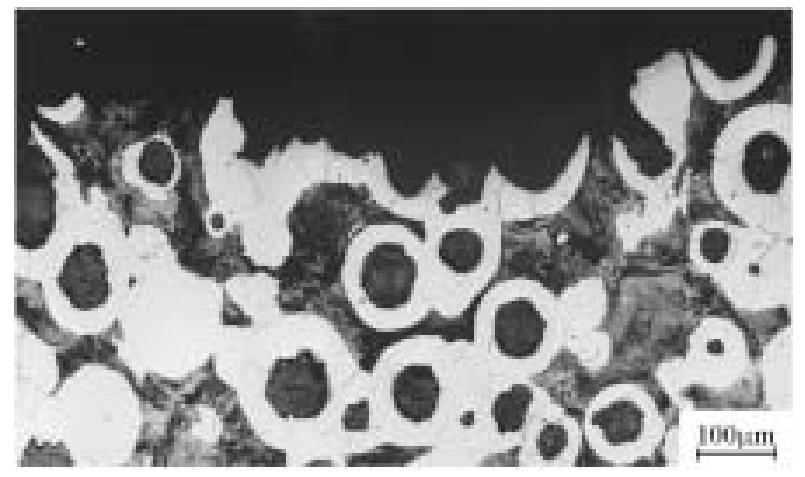

$\mathrm{E} 144, \mathrm{~T}=140{ }^{\circ} \mathrm{C}, K C V=15.4 \mathrm{~J} / \mathrm{cm}^{2}$

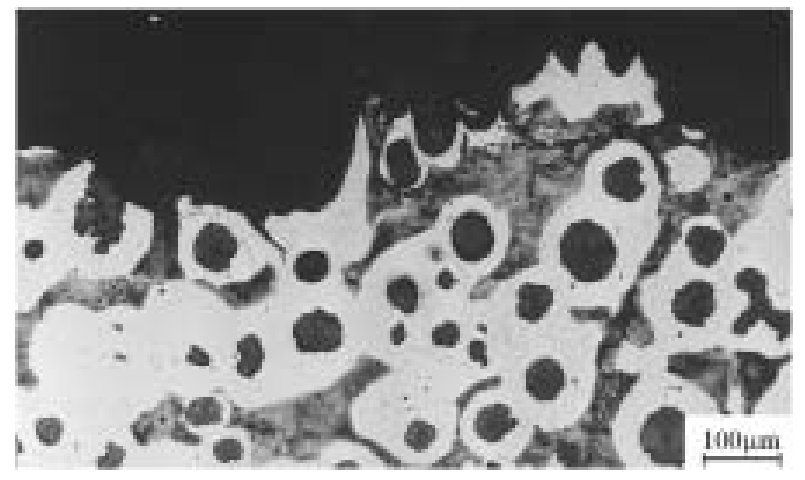

$\mathrm{E} 151, \mathrm{~T}=60{ }^{\circ} \mathrm{C}, K C V=8 \mathrm{~J} / \mathrm{cm}^{2}$

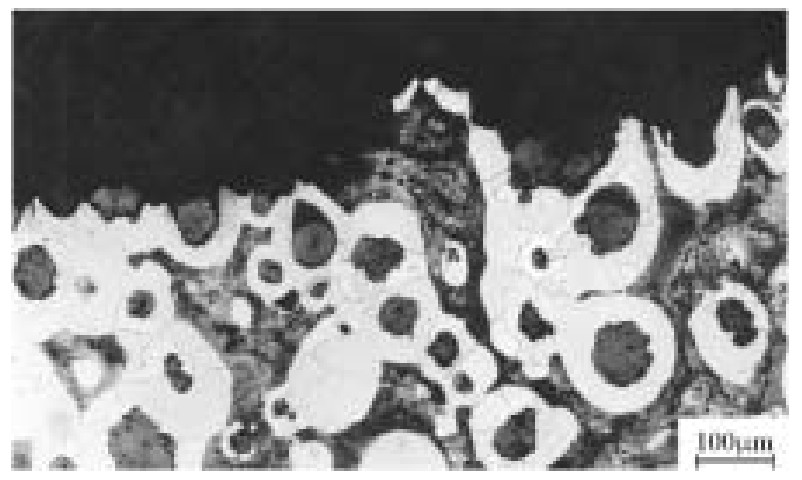

$\mathrm{E} 171, \mathrm{~T}=100^{\circ} \mathrm{C}, K C V=14.6 \mathrm{~J} / \mathrm{cm}^{2}$

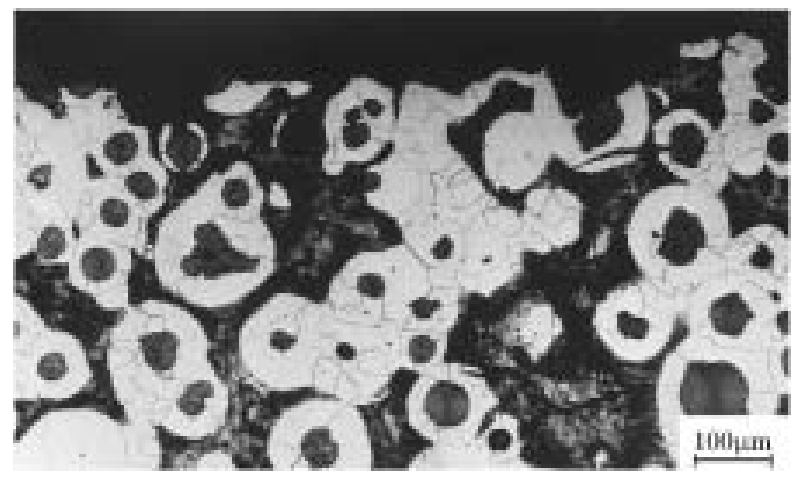

E $144, \mathrm{~T}=20^{\circ} \mathrm{C}, K C V=5 \mathrm{~J} / \mathrm{cm}^{2}$

Fig. 1. Typical sections of impacted test specimens (melt, test temperature and notch impact toughness are specified below each micrograph)

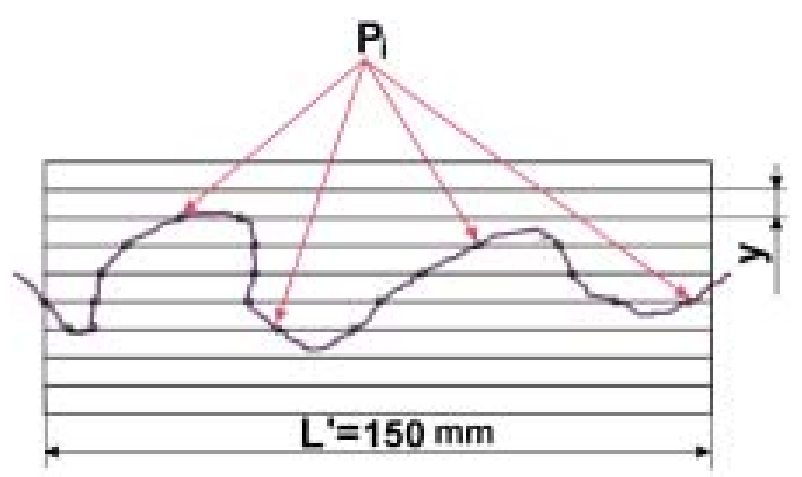

a)

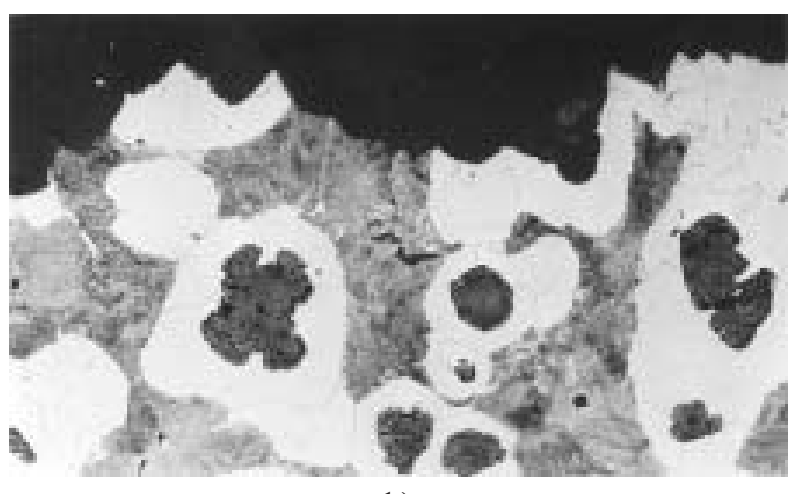

b)

Fig. 2. Method for the determination of $R_{V}$ a) scheme and b) fracture profile

mated by best fit. To summarize this section, an increase in ferrite content in the matrix decreases the transition temperature. A SiC addition to the melt results in a higher upper-shelf toughness and a lower transition temperature when compared to nodular cast iron with a FeSi addition.

\subsection{Notch vs. unnotched impact toughness}

The role of the test methodology, (i.e. use of a V-notched or an unnotched prismatic bar) on the impact characterization of nodular cast iron is discussed in this section. A difference in the characterization capability of the two approaches (i.e. notched vs. unnotched) is expected since the notch concentrates high stresses only in a limited material volume at the crack tip and develops a triaxial stress state favoring a brittle material response. On the other hand, in the unnotched specimen a considerably larger material volume is subjected to high stresses while the stress triaxiality is low. The wide range of material microstructures characterizing the present melts of nodular cast iron provides experimental data that can be used in the assessment of the two impact test methods. Two microstructural characteristics, one related to the 


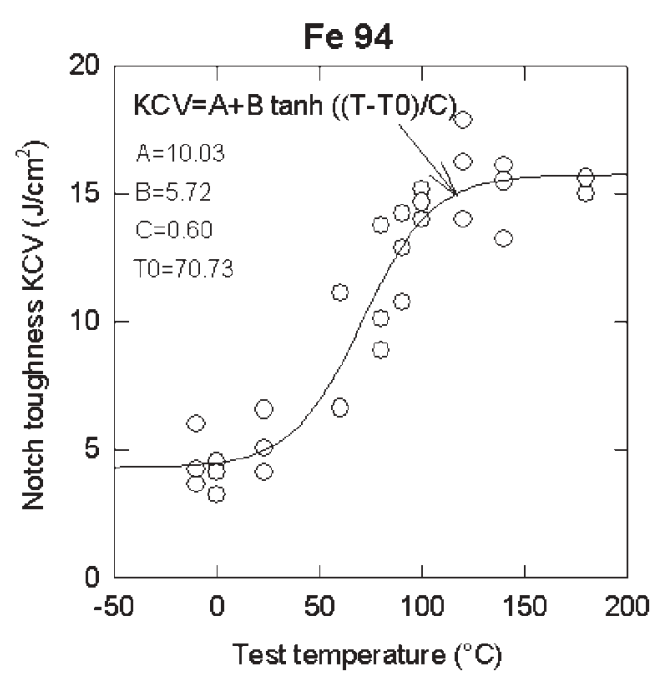

Fig. 3 Transition behavior of a nodular cast iron with Fe 94 matrix

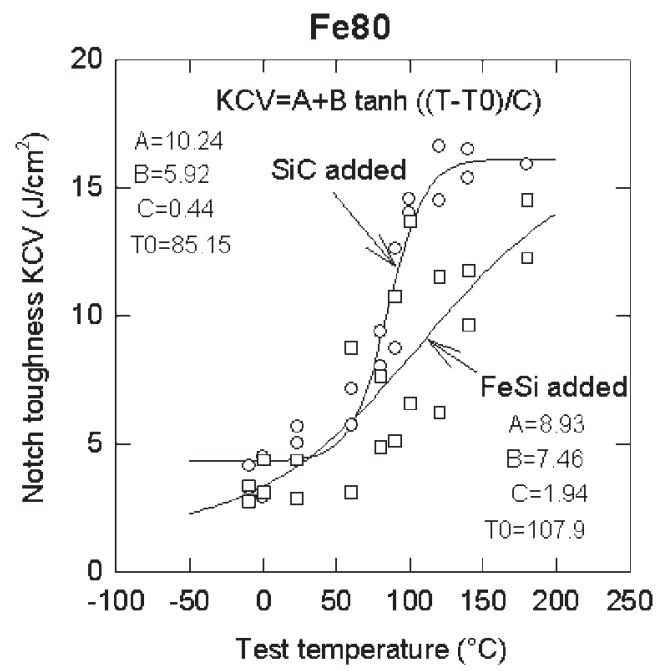

Fig. 4 Transition behavior of nodular cast irons with Fe 80 matrix

matrix and the other to the graphite nodules are separately considered in order to investigate their influence on the impact tests data. Therefore, notched and unnotched impact toughness at room temperature is plotted as a function of the ferrite content in the matrix in Fig. 5 and as a function of the graphite nodule count in Fig. 6.

The unnotched impact toughness test (i.e. KC0) shows the greatest sensitivity to the ferrite content. Fig. 5 shows also a steep gradient in the dependence on the ferrite content above $70 \%$. A $10 \%$ increase in ferrite content is found to result in a dramatic increase, from $15 \mathrm{~J} / \mathrm{cm}^{2}$ to $80 \mathrm{~J} / \mathrm{cm}^{2}$, in $\mathrm{KC} 0$. The trend of the notched (i.e. $K C V$ ) data is less defined with a large scatter determined above $70 \%$ of the ferrite content. As far as the dependence of $\mathrm{KCO}$ and $\mathrm{KCV}$ on the graphite nodule count, see Fig. 6, both data sets show increasing impact toughness with nodule count but the scatter is quite significant in both cases. To summarize this

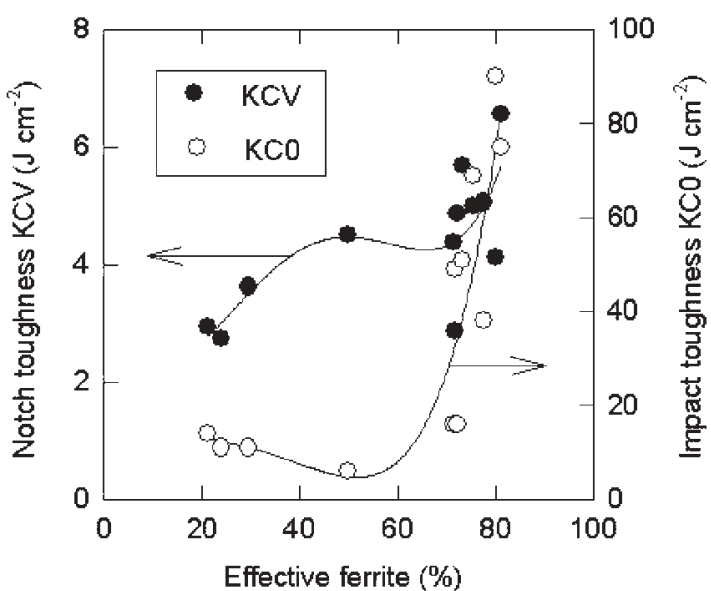

Fig. 5 Role of ferrite in the matrix on impact toughness at room temperature

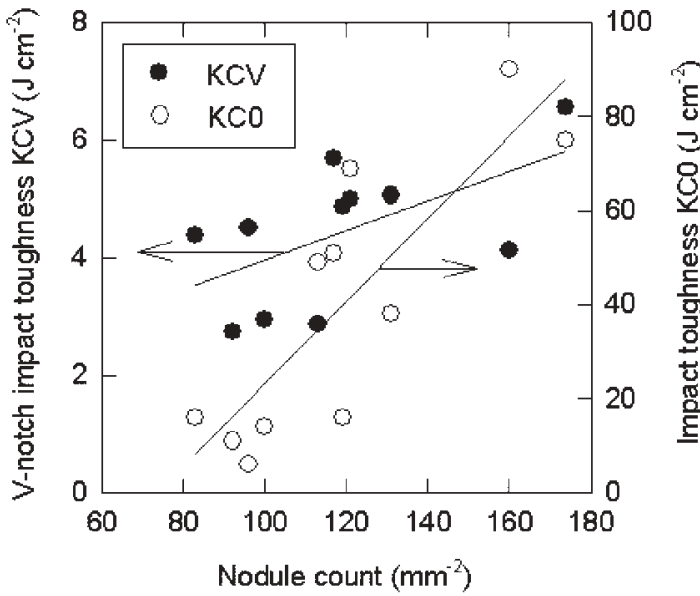

Fig. 6 Role of graphite nodule count on impact toughness at room temperature

section, it appears that the use of the unnotched specimen geometry for impact characterization of nodular cast iron provides a better resolution of material response than the Charpy notch test method.

\subsection{Fracture surface roughness}

In this section the capability of the surface topography in discriminating microstructure-dependent material behavior is investigated. Generally, the fracture roughness is directly influenced by the size and distribution of graphite. The presence of different fracture mechanisms, such as cavitations around nodules, dimple formation, cleavage of ferrite capsules and cleavage of pearlite regions, influence the degree of roughness of the surface.

In the previous section it was concluded that the use of unnotched specimen for impact characterization of nodular cast iron provides a better resolution of impact response of nodular 
cast iron than the notched bar method. Initially, the $\mathrm{KC} 0$ data obtained by testing the present wide range of nodular cast iron at room temperature is plotted against the fracture surfaces roughness $R_{V}$. The remarkably linear correlation of Fig. 7 demonstrates a close dependence between the two parameters. To investigate this aspect, the fracture profiles obtained during the transition characterization testing of nodular cast iron were studied by optical microscopy and the fracture roughness determined.

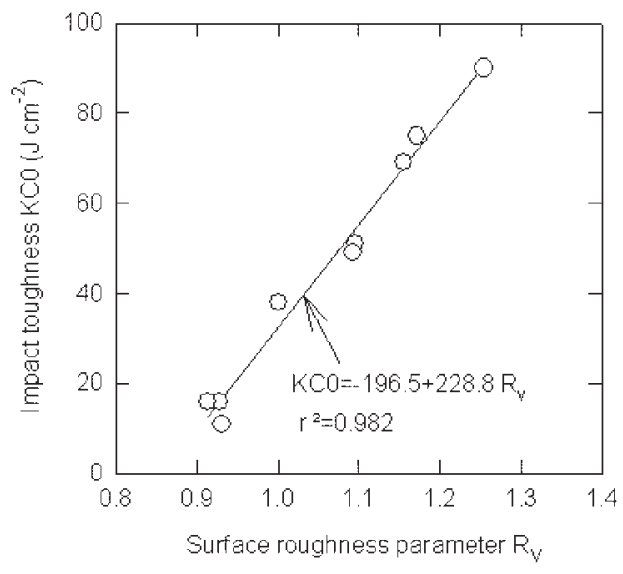

Fig. 7 Correlation of unnotched impact toughness and roughness of fracture profiles

The resulting trends in the vertical roughness parameter $R_{V}$ characterization as a function of the test temperature are shown in Figs. 8 and 9. The nodular cast irons considered were characterized by a percentage of effective ferrite in the matrix of around $70 \%$, which should be associated to microstructural-induced scatter due to their heterogeneity. Vertical roughness $R_{V}$ data are presented in separate plots on the basis of addition type. Inspection of Figs. 8 and 9 show that in all cases the vertical roughness $R_{V}$ exhibits a "transition" trend although in a less pronounced way than the plots of the Charpy impact. This transition-type response is more pronounced in the $\mathrm{SiC}$-added nodular cast iron, which also showed a well-defined transition behavior in the Charpy tests, Fig. 3 and 4. Fig. 8 confirms that, to completely determine the transition behavior of FeSi-added nodular cast iron, a wider range of test temperatures may be required.

Another interesting feature of the $R_{V}$ vs. $T$ plot is the distinct material response for the different microstructures. In the plots, each data set is associated to microstructural details such as nodule count and graphite form. Fig. 8 shows that in the presence of a similar nodule count of the FeSi-added melts, the quality of graphite nodules can significantly increase the surface topography and, indirectly, see Fig. 7, improve the impact performance. It is expected that this improvement would disappear within the scatter of the standard Charpy test method. Alternatively, Fig. 9 shows that in the presence of a similar quality of graphite nodules of the $\mathrm{SiC}$-added melts, an increase in nodule count significantly reduces the surface topography especially at low temperatures. Again, the fracture surface topography could signal a reduced impact perfor- mance, possibly difficult to identify by the standard Charpy test method.

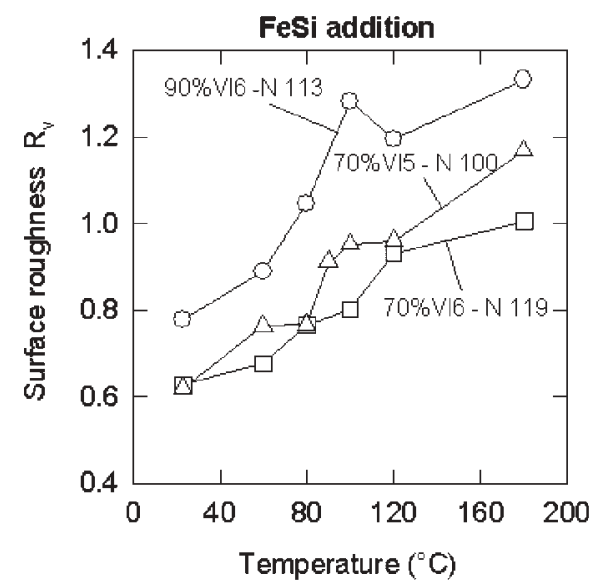

Fig. 8 Vertical surface roughness $R_{V}$ dependence on impact test temperature for FeSi-added melts

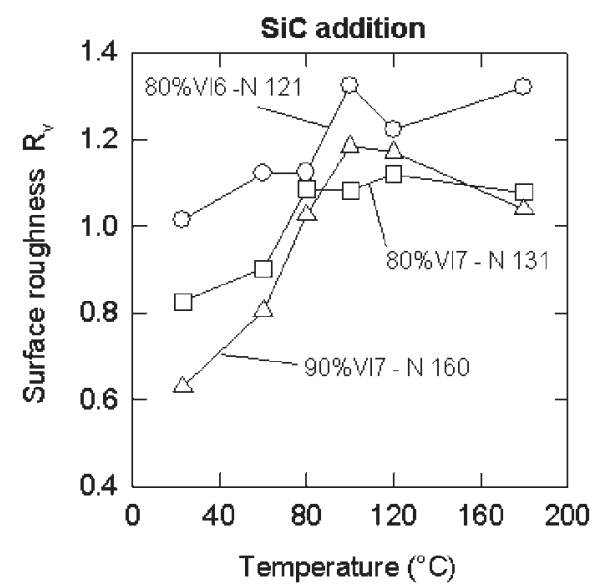

Fig. 9 Vertical surface roughness $R_{V}$ dependence on impact test temperature for SiC-added melts

\section{Conclusions}

The aim of this study was to determine the transition response of nodular cast iron and to investigate the possibility of using fracture surface topography indicators to discriminate microstructurerelated material response. Therefore, nodular cast irons with a wide range of microstructures were characterized and tested. The following conclusions are advanced:

- Nodular cast irons with a high percentage of ferrite showed the transition behaviour when Charpy $V$-notch tested at temperatures in the range from $-10{ }^{\circ} \mathrm{C}$ to $180{ }^{\circ} \mathrm{C}$.

- Nodule count and percentage of ferrite in the matrix significantly affect notch and unnotched impact toughness of nodular cast iron. 
- The unnotched toughness $\mathrm{KC} 0$ test method is more sensitive and precise in describing the role of ferrite on the impact behavior of ductile iron when compared to the notch toughness $\mathrm{KCV}$ test method.

- The fracture surface roughness parameter $R_{V}$ determined in impacted specimens defines trend similar to the ductile-to-brittle transition behavior.

- $\mathrm{SiC}$ addition to ductile iron results in a superior ductile-brittle transition behavior when compared to the FeSi addition.

- The role of microstructural parameters, such as quality of graphite nodule, nodule count and ferrite content in the matrix, on mate- rial performance can be discriminated using fracture surface roughness.

\section{Acknowledgements}

Financial support of the Scientific Grant Agency of Ministry of Education of Slovak Republic and Slovak Academy of Sciences (grant No.1/0027/03), of the SK/CZ Cooperation Project (No. 063/117) and of the CETRA program at University of Žilina, Slovakia.

\section{References}

[1] DAVIS, J. R. ED.: ASM Specialty Handbook - Cast Irons, ASM International, 1996.

[2] KONEČNÁ, R., HADZIMOVÁ, B., NICOLETTO, G., MATEJKA, M.: Role of ferrite content on the impact strength of nodular cast irons. Materials Engineering, 10, 2003, Žilina, ISSN 1335-0803.

[3] KONEČNÁ, R., NICOLETTO, G., HADZIMOVÁ, B., LEJČEK, P.: Influence of temperature and micropurity of ferrite on failure behaviour of ductile iron. In.: Fractography 2003, Stará Lesná, Slovakia, 2003, 224-232.

[4] KONEČNÁ, R., SKOČOVSKÝ, P.: Relationship between microstructure and impact toughness of cast irons with transient forms of graphite. Kovové materiály 3 - S, SAV, Bratislava, 1998, pp. 43 - 48.

[5] BENKO, P., SKOČOVSKÝ, P.: Influence of modification on quantitative-microfractographic characteristics of silumin AlSil0MgMn (in Slovak). Materials Engineering 2/1996, University of Žilina, 1996, pp. 64-72, ISSN 1335-0803. 